\title{
HUBUNGAN LAMA DUDUK DAN SIKAP DUDUK DENGAN KELUHAN NYERI PUNGGUNG BAWAH (LOW BACK PAIN) PADA PEKERJA PEMOTONG IKAN
}

\author{
RAHMAD GURUSINGA ${ }^{1}$, TATI MURNI KAROKARO ${ }^{2}$, \\ KARDINA HAYATI ${ }^{3}$, SARMANA ${ }^{4}$ BUNGA BR SARAGIH $^{5}$
}

\author{
Institut Kesehatan MEDISTRA Lubuk Pakam \\ Jl. Sudirman No 38 Lubuk Pakam Kab.Deli Serdang, Sumatera Utara. \\ e-mail : rahmad.gurusinga@gmail.com \\ DOI : https://doi.org/10.35451/jkg.v4i1.835
}

\begin{abstract}
Low back pain (LBP) is a very common world health problem, which causes activity restrictions and also absenteeism from work. Low back pain can reduce human productivity, 50-80\% of workers worldwide have experienced low back pain where almost a third of their age have experienced some type of low back pain which is the second disease after the flu. The purpose of this study was to determine the relationship between sitting and sitting posture with complaints of low back pain among fish cutter workers at UD. Dumbo Jaya Group, Kota Galuh Village, Perbaungan District, Serdang Bedagai Regency. The research method uses an analytical survey with a cross sectional design. The number of samples as many as 31 fish cutter workers, data collection using questionnaires and data analysis using the chi-square test with a significant level of $95 \%$ or $p \leq a(0.05)$. The results showed that there was a significant relationship between length of sitting and complaints of low back pain in fish cutter workers $P=0.013$ $<=0.05$ and there was a significant relationship between sitting posture and complaints of low back pain in fish cutter workers $P=0.039<=0.05$. It is recommended for fish cutter workers to be able to arrange rest hours and a good sitting posture so that lower back pain does not occur.
\end{abstract}

\section{Keywords: Long sitting, Sitting posture, Low Back Pain}

\section{PENDAHULUAN}

Nyeri Punggung Bawah (NPB) merupakan masalah kesehatan dunia yang sangat umum, yang menyebabkan pembatasan aktivitas dan juga ketidakhadiran kerja dan penderita yang mengalaminya menjadi tidak produktif sehingga akan menyebabkan beban ekonomi yang sangat besar bagi individu, keluarga, masyarakat, maupun pemerintah (Patrianingrum, 2015).

Nyeri punggung bawah dapat menurunkan produktivitas manusia, 50$80 \%$ pekerja di seluruh dunia pernah mengalami nyeri punggung bawah dimana hampir sepertiga dari usianya pernah mengalami beberapa jenis nyeri punggung bawah yang merupakan penyakit kedua setelah flu yang dapat membuat seseorang sering berobat ke dokter sehingga memberi dampak buruk bagi kondisi sosial ekonomi dengan berkurangnya hari kerja juga penurunan produktivitas (Tanderi, 2017)

Low back pain (LBP) didefinisikan sebagai suatu kondisi tidak spesifik yang mengakibatkan rasa nyeri, pegal yang dirasakan pada punggung bagian bawah, kondisi yang tidak spesifik tersebut mengacu pada nyeri akut atau kronik dan ketidaknyamanan pada daerah lumbosacral. Keluhan nyeri punggung 
bawah secara umum menjadi masalah kesehatan (Karisma, 2017).

Lama duduk dapat berdiri sendiri sebagai factor resiko yang signifikan untuk keluhan nyeri punggung bawah, kecuali jika dikombinasikan dengan sikap duduk yang salah dan getaran pada tubuh maka mungkin akan meningkatkanresiko berkembangkannya nyeri punggung bawah, Terlalu lama duduk dengan posisi yang kurang tepat membuat orang capek dan kurang efesien bekerja, posisi lordisis yaitu membungkuk dengan beban pada tulang belakang yang terlalu banyak merupakan gangguan otot utamanya otot perut dan otot punggung yang menjadi sebab nyeri punggung bawah (Rachmat et all,2019).

$$
\text { Menurut Parjoto }
$$
beberapa macam posisi duduk adalah yang pertama Posisi duduk tegak dengan sudut 90 derajat tanpa sandaran dapat mengakibatkan beban pada daerah lumbal. Hal ini disebabkan oleh otot untuk meluruskan tulang punggung dan daerah lumbal yang menahan beban yang lebih besar. Kedua posisi Duduk condong kedepan yaiti dengan Posisi duduk dengan badan condong kedepan atau membungkuk dengan sudut 70 derjat dapat menambah gaya pada discus lumbalis kurang lebih $90 \%$. Posisi leher condong kedepan dengan badan membungkuk mengakibatkan beban kerja otot berkurang namun beban yang ditahan discus meningkat. Sedangkan yang ketiga posisi duduk Menyandar yaitu Posisi menyandar mengikuti proporsi tubuh dapat mengurangi tekanan discus $5 \%$ sehingga posisi yang paling nyaman, namun permasalahan pada posisi target visual terlalu auh atau terlalu rendah.

Posisisaat duduk dipengaruhi oleh sudut sandaran punggung, sudut dudukan kursidengan keempukan busa, dantidakadanyasandaranpunggung yang memiliki sudut $110^{\circ}-130^{\circ}$ adalah tumpuan yang paling ideal karena menghasilkan tekanan paling rendah bagi diskus intervertebralis dengan kerja otot yang paling ringan. Dudukan kursi yang memiliki sudut $5^{\circ}$ dan sanggahan tangan juga dapat menurunkan tekanan diskus intervertebralis dan kerja otot saat duduk (Widiasih, 2015).

Durasi lama duduk terdiri dari durasi singkat $<1$ jam per hari, durasi sedang 1-2 jam perhari dan durasi lama yaitu $>2$ jam perhari. Selam berkontraksi otot memerlukan oksigen, jika gerakan berulang-ulang dari otot menjadi terlalu cepat sehingga oksigen belum mecapai jaringan maka akan terjadi kelelahan otot,lama duduk yang lebih dari 9 jam dalam sehari dapat mengurangi lubrikasi pada sendi dan menyebabkan kekakuan sekitar $60 \%$ pekerja mengeluh mengalami nyeri punggung bawah akibat kurang gerak dan posisi duduk yang tidak berubahubah dalam waktu yang lama. Duduk dengan waktu lama dan posisi yang salah dapat menyebabkan otot-otot pinggang menjadi tegang dan dapat merusak jaringan lunak sekitarnya. Bila keadaan ini berlanjut akan menyebabkan penekanan pada bantalan saraf tulang belakang (Wulandari,2010).

Permasalahan mendasar dari pekerja pemotong ikan di Usaha Dagang Dumbo Jaya tersebut adalah dari lama duduk mereka saat bekerja dan sikap duduk mereka yang membungkuk dengan waktu 2 jam sampaidengan 9 jam perharinya, pekerja harus bekerja dengan resiko yang besar dan akan berdampak pada kesehatan para pekerja tersebut. Para pekerja perlu diberikan perhatian dan perlindungan dalam proses pekerjaan dalam sisi keselamatan dan kesehatan kerja (K3) dan edukasi terhadap resiko pekerjaan yang dilakukan. Selain hal tersebut penelitian ini belum pernah dilakukan sebelum nya dan perlu diakukan penelitian. 


\section{METODE}

Penelitian ini merupakan penelitian kuantitatif yang bersifat survey analitik dengan menggunakan rancangan cross sectional. Pada penelitian ini dilakukan terhadap variabel independen yaitu sikap duduk dan lama duduk dan variabel dependen yaitu keluhan nyeri punggung bawah (LBP).

Pengambilan sampel dilakukan dengan perhitungan rumus lameshow dengan jumlah sampel sebanyak 31 sampel dengan populasi 45 pekerja pemotong ikan. Teknik pengambilan sampel dengan menggunakan data primer berupa wawancara yang dilakukan dengan berpedoman pada kuesioner.Tempat penelitian dilaksanakan di UD.Dumbo Jaya Group Desa Kota Galuh Kecamatan Perbaungan Kabupaten Serdang Bedagai, Sumut. Analisis data dengan menggunakan Uji chi-square dengan tingkat signifikan $95 \%$ ataup $\leq \mathrm{a}(0,05)$

\section{HASIL}

Tabel 1. Karakteristik Responden Berdasarkan Umur, Pendidikan Terakhir dan Masa Kerja

\begin{tabular}{cccc}
\hline No & Karakteristik & F & \% \\
\hline $\mathbf{1 .}$ & Umur & & \\
& $20-25$ & 8 & 25,8 \\
& $26-31$ & 6 & 19,4 \\
& $32-45$ & 17 & 54,8 \\
\hline & Total & $\mathbf{3 1}$ & $\mathbf{1 0 0 , 0}$ \\
\hline $\mathbf{2}$ & Pendidikan & & \\
terakhir & & \\
& SD & 7 & 22,6 \\
& SMP & 11 & 35,5 \\
& SMA/SMK & 13 & 41,9 \\
\hline \multirow{4}{*}{ Total } & $\mathbf{3 1}$ & $\mathbf{1 0 0 , 0}$ \\
\hline & Masa Kerja & & \\
& 1-2 Thn & 21 & 67,7 \\
& 3-4 Thn & 6 & 19,4 \\
& 5-6 Thn & 4 & 12,9 \\
\hline & Total & $\mathbf{3 1}$ & $\mathbf{1 0 0 , 0}$ \\
\hline
\end{tabular}

Berdasarkan Tabel 1. di atas dapat diketahui bahwa mayoritas pekerja yang berumur 32-45 tahun berjumlah $17(54,8 \%)$ dan minoritas umur 26-31 tahun berjumlah 6 orang $(19,4 \%)$ dan berdasarkan pendidikan mayoritas SMA sebanyak 13 orang $(41,9 \%)$ dan minoritas Pendidikan terkahir SD sebanyak 7 orang $(22,6 \%)$, sedangkan Masa Kerja mayoritas dengan masa $1-2$ thn 21 orang $(67,7 \%)$ dan minoritas masa kerja 5-6 Thn 4 orang ( $12,9 \%)$.

Tabel 1 Distribusi Responden Berdasarkan Lama Duduk

\begin{tabular}{ccc}
\hline $\begin{array}{c}\text { Kategori } \\
\text { Lama Duduk }\end{array}$ & $\mathbf{f}$ & $\mathbf{\%}$ \\
\hline Tidak Lama & 4 & 12,9 \\
Lama & 27 & 87,1 \\
\hline Total & $\mathbf{3 1}$ & $\mathbf{1 0 0 , 0}$ \\
\hline
\end{tabular}

Berdasarkan Tabel 2. Diketahui bahwa Mayoritas responden mengalami Lama duduk berjumlah 27 orang $(87,1 \%$ dan minoritas responden yang mengalami tidak lama duduk berjumlah 4 orang $(12,9 \%)$.

Tabel 3.Distribusi Responden Berdasarkan Sikap Duduk

\begin{tabular}{llc}
\hline $\begin{array}{c}\text { Kategori } \\
\text { Sikap Duduk }\end{array}$ & $\mathbf{f}$ & $\mathbf{\%}$ \\
\hline Ergonomi & 11 & 35,5 \\
TidakErgonomi & 20 & 64,5 \\
\multicolumn{1}{c}{ Total } & $\mathbf{3 1}$ & $\mathbf{1 0 0 , 0}$ \\
\hline
\end{tabular}

Berdasarkan tabel 3. Mayoritas sikap duduk tidak ergonomi berjumlah 20 orang $(64,5 \%)$ dan minoritas pekerja yang sikap duduknya ergonomi berjumlah 11 orang $(35,5 \%)$.

Tabel2. Distribusi Responden Berdasarkan Keluhan Nyeri Punggung Bawah (LBP)

\begin{tabular}{lcc}
\hline \multicolumn{1}{c}{ Kategori LBP } & f & \% \\
\hline Keluhan Menengah & 3 & 9,7 \\
Keluhan Tinggi & 26 & 83,9
\end{tabular}




\begin{tabular}{|c|c|c|c|}
\hline $\begin{array}{l}\text { KeluhanSangat } \\
\text { Tinggi }\end{array}$ & 2 & 6,5 & $\begin{array}{l}\text { keluhan nyeri punggung tinggi berjumlah } \\
26 \text { orang }(83,9 \%) \text { dan minoritas yang }\end{array}$ \\
\hline Total & 31 & 100,0 & mengalami keluhan nyeri punggur \\
\hline
\end{tabular}

Tabel 5.Hubungan Lama Duduk Dengan Keluhan Nyeri Punggung Bawah (LBP)

Pada Pekerja Pemotong Ikan

\begin{tabular}{|c|c|c|c|c|c|c|c|c|c|}
\hline \multirow{3}{*}{$\begin{array}{c}\text { Kategori } \\
\text { Lama } \\
\text { Duduk }\end{array}$} & \multicolumn{9}{|c|}{ Keluhan Nyeri Punggung Bawah (LBP) } \\
\hline & \multicolumn{2}{|c|}{$\begin{array}{c}\text { Keluhan } \\
\text { Menengah }\end{array}$} & \multicolumn{2}{|c|}{$\begin{array}{c}\text { Keluhan } \\
\text { Tinggi }\end{array}$} & \multicolumn{2}{|c|}{$\begin{array}{c}\text { Ke luhan } \\
\text { Sangat } \\
\text { Tinggi }\end{array}$} & \multicolumn{2}{|c|}{ Total } & \multirow[t]{2}{*}{$\begin{array}{c}P \\
\text { Value }\end{array}$} \\
\hline & $\mathrm{n}$ & $\%$ & $\mathrm{n}$ & $\%$ & $\mathrm{n}$ & $\%$ & $\mathrm{n}$ & $\%$ & \\
\hline $\begin{array}{l}\text { Tidak } \\
\text { Lama }\end{array}$ & 2 & 50,0 & 2 & 50,0 & 0 & 0 & 4 & 100 & 0,013 \\
\hline Lama & 1 & 3,7 & 24 & 88,8 & 2 & 7,5 & 27 & 100 & \\
\hline Total & 3 & 9,7 & 26 & 83,8 & 2 & 6,5 & 31 & 100 & \\
\hline
\end{tabular}

Berdasarkan Tabel 5. Menunjukkan bahwa ada hubungan yang signifikan antara Lama duduk dengan Keluhan Nyeri Punggung Bawah (Low Back Pain) Pada Pekerja Pemotong Ikan Di UD. Dumbo Jaya Group Desa Kota Galuh Kecamatan Perbaungan Kabupaten Serdang Bedagai Tahun $2021(P=0,013<0,05)$.

Tabel3. Hubungan Sikap Duduk Dengan Keluhan Nyeri Punggung Bawah (LBP) Pada Pekerja Pemotong Ikan

\begin{tabular}{|c|c|c|c|c|c|c|c|c|c|}
\hline \multirow{3}{*}{$\begin{array}{c}\text { Kategori } \\
\text { Sikap } \\
\text { Duduk }\end{array}$} & \multicolumn{9}{|c|}{ Keluhan Nyeri Punggung Bawah (LBP) } \\
\hline & \multicolumn{2}{|c|}{$\begin{array}{c}\text { Keluhan } \\
\text { Menenga } \\
\mathrm{h}\end{array}$} & \multicolumn{2}{|c|}{$\begin{array}{c}\text { Keluhan } \\
\text { Tinggi }\end{array}$} & \multicolumn{2}{|c|}{$\begin{array}{c}\text { Keluhan } \\
\text { Sangat } \\
\text { Tinggi }\end{array}$} & \multicolumn{2}{|c|}{ Total } & \multirow[t]{2}{*}{$\begin{array}{c}P \\
\text { Value }\end{array}$} \\
\hline & $\mathrm{n}$ & $\%$ & $\mathrm{n}$ & $\%$ & $\mathrm{n}$ & $\%$ & $\mathrm{n}$ & $\%$ & \\
\hline Ergonomi & 3 & 27,3 & 7 & 63,7 & 1 & 9,0 & 11 & 100 & 0,039 \\
\hline $\begin{array}{l}\text { Tidak } \\
\text { Ergonomi }\end{array}$ & 0 & 0 & 19 & 95,0 & 1 & 5,0 & 20 & 100 & \\
\hline Total & 3 & 9,7 & 26 & 83,8 & 2 & 6,5 & 31 & 100 & \\
\hline
\end{tabular}

Berdasarkan Tabel 6. Menunjukkan ada hubungan yang signifikan antara Sikap Duduk Dengan Keluhan Nyeri Punggung Bawah (Low Back Pain) Pada Pekerja Pemotong Ikan Di UD. Dumbo Jaya Group Desa Kota Galuh Kecamatan Perbaungan Kabupaten Serdang Bedagai Tahun $2021(P=0,039<0,05)$

\section{PEMBAHASAN}

Berdasarkan hasil analisis penelitian pada Tabel1. di atas dapat diketahui bahwa pada pekerja di
UD.Dumbo Jaya Group mayositas berumur $32-45$ tahun berjumlah 17 $(54,8 \%)$ dan minoritas umur 26-31 tahun berjumlah 6 orang $(19,4 \%)$ dan 
dari tingkat Pendidikan mayoritas SMA sebanyak 13 orang $(41,9 \%)$ minoritas SD sebanyak 7 orang (22,6\%), sedangkan dilihat dari mayoritas dengan masa kerja 1-2 thn 21 orang ( $67,7 \%)$ dan minoritas masa kerja 5-6 thn 4 orang $(12,9 \%)$.

Menurut Andini, (2015) sejalan dengan meningkatnya usia akan terjadi degenerasi pada tulang dan keadaan ini mulai terjadi di saat seseorang berusia 30 tahun. Padausia 30 tahun terjadi degenerasi yang berupa kerusakan jaringan, penggantian jaringan menjadi jaringan parut, pengurangan cairan. Hal tersebut menyebabkan stabilitas pada tulang dan otot menjadi berkurang. Semakin tua seseorang, semakin tinggi risiko orang tersebut tersebut mengalami penurunan elastisitas pada tulang yang menjadi pemicu timbulnya gejala nyeri punggung bawah dan menurut (Notoadmodjo,2012) yaitu kreteria insklusif dimana masa kerja lebih dari 1 tahun rentan terhadap penyakit akibat kerja.

Hasil penelitian pada tabel 2 . Tentang Lama Duduk yang Tidak lama berjumlah 4 orang $(12,9 \%)$ sedangkan pekerja dengan Lama Duduk yang Lama berjumlah 27 orang (87,1 \%). Dimana, semakin lama durasi kerja maka semakin tinggi resiko keluhan nyeri punggung bawah, duduk dalam jangka waktu yang cukup lama dapat menyebabkan keluhan yang timbul antara lain karena pembebanan yang terus terjadi saat duduk lama (Jaleha,2015).

Hasil penelitian pada tabel 3 . tentang Sikap Duduk menunjukkan bahwa pekerja dengan sikap duduk yang Tidak Ergonomi berjumlah 20 orang $(64,5 \%)$ dan pekerja yang sikap duduk Ergonomi berjumlah 11 orang $(35,5 \%)$, dimanaPostur saat duduk dipengaruhi oleh sudut sandaran pada punggung dimana dudukan kursi yang memiliki sudut $5^{\circ}$ dan sanggahan tangan juga dapat menurunkan tekanan diskus intervertebralis dan kerja otot saat duduk(Widiasih, 2015).

Hasil penelitian pada tabel 4. tentang keluhan nyeri punggung bawah menunjukkan bahwa pekerja dengan keluhan nyeri punggung bawah yaitu yang mengalami keluhan menengah sebanyak 3 orag $(9,7 \%)$, keluhan tinggi sebanyak 26 orang ( 83,9\%) dan keluhan sangat tinggi sebanyak 2 orang $(6,5 \%)$, dimanaKeluhan nyeri punggung bawah yaitu nyeri, spasme, dan adanya keterbatasan fungsional yang berhubungan dengan mobilitas lumbal, yang menyebabkan perubahan fisiologi pada otot tersebut yaitu berkurangnya masa ototpenurunan kekuatan otot, akhirnya menimbulkan penurunan aktifitas fungsionalnya (Hill, 2006 dalam Yani, 2018).

Berdasarkan hasil uji diperoleh nilai probabilitas $(P)=(0,013)<\mathrm{a}=(0,05)$. Hal ini berarti dapat diketahui bahwasannya ada hubungan yang signifikan antara Lama Duduk Dengan Keluhan Nyeri Punggung Bawah (LBP) dan uji juga diperoleh nilai probabilitas $(P)=(0,039)<\mathrm{a}=(0,05)$. Hal ini berarti dapat diketahui bahwasannya ada hubungan yang signifikan antara Sikap duduk Dengan Keluhan Nyeri Punggung Bawah (LBP) Pada Pekerja Pemotong Ikan Di UD. Dumbo Jaya Group Desa Kota Galuh Kec. Perbaungan Kab. Serdang Bedagai.

Penelitian ini sejalan dengan penelitian yang telah dilakukan oleh Zatadin \& Zammira (2018), menunjukkan ada hubungan antara posisi duduk dengan lama duduk terhadap kejadian nyeri punggung bawah (NBP) pada penjahit sektor informal di kecamatan laweyan kota Surakarta, dengan nilai signifikan 0,006 $<0,05$.

\section{KESIMPULAN}

Dari hasil penelitian dapat disimpulkan bahwa Ada hubungan yang 
signifikan antara lama duduk dengan keluhan nyeri punggung bawah pada pekerja pemotong ikan di UD.Dumbo Jaya Group dengan nilai signifikan $(P)=$ $(0,013)<a=(0,05)$ danAda hubungan yang signifikan antara sikap duduk dengan keluhan nyeri punggung bawah pada pekerja pemotong ikan di UD.Dumbo Jaya Group dengan nilai signifikan $(P)=(0,039)<a=(0,05)$.

\section{DAFTAR PUSTAKA}

Andini (2015). Risk Factors of Low Back Pain in Wikers. J. Majority.UniversitasLampung. 4(1):12-19

Jaleha, B. (2015). Hubungan Durasi Duduk Dengan RisikoTerjadinya Scoliosis Lumbal. SkripsiUniversitasMuhammadiy ahSurakartaAvailableat:http://e prints.ums.ac.id/36706/24/NAS KAH\%20PUBLIKASI.pdf

Karisma, I A. (2017).Epidemiologi Keluhan Low Back Pain padakelompok Amertha Segara Denpasar Tahun 2017. Skripsi, Universitas Udayana, Availableat:https://sinta.unud.a c.id/uploads/dokumen_dir/

NotoatmodjoS.

(2012).Promosi Kesehatan dan Perilaku Kesehatan. Jakarta: PT Rineka Cipta.

Rachmat, N., Utomo, P. C., Sambada, E. R., \& Andyarini, E. N. (2019). Hubungan Lama Duduk dan Sikap Duduk Terhadap Keluhan Nyeri Punggung Bawah Pada Penjahit Rumahan Di Kecamatan Tasikmadu', Journal of Health Science and Prevention, 7985http://jurnalfpk.uinsby.ac.id/in dex.php/jhsp/article/view/204

Tanderi, A.T., Ajoe K., Hendrianingtyas, (2017). Hubungan Kemampuan Fungsional dan Derajat Nyeri pada Pasien Low Back Pain
Mekanik di Instalasi Rehabilitasi Medik RSUP Dr. Kariadi Semarang. Jurnal Kedokteran Diponegoro, 6(1): 63-72.

Widiasih, G. (2015). Hubungan Posisi Belajar dan Lama Duduk dengan Kejadian NyeriPunggung Bawah. Mahasiswa PSPD FKIK UIN Jakarta : Available at: http://repository.uinjkt.ac.id/dsp ace/bitstream/123456789/29488 /1/GHINA\%20WIDIASIHFKIK.pdf

Wulandari, I. D. (2010) Hubungan lama dan sikap duduk perkuliahan terhadap keluhan nyeri punggung bawah miogenik pada mahasiswa di universitas muhammadiyah surakarta',Pena Jurnal IImu Pengetahuan dan Teknologi, Available at: https://jurnal.unikal.ac.id/index. php/pena/article/viewFile/149/14 9

Zatadin \&Zammira. M. (2018). Hubungan posisi duduk dan lama duduk terhadap kejadian nyeri punggung bawah (NPB) pada penjahit sektor informal di kecamatan laweyan kota surakarta. Surakarta. http://eprints.ums.ac.id/58136/ 